Hydrology and Earth System Sciences, 10, 101-112, 2006

www.copernicus.org/EGU/hess/hess/10/101/

SRef-ID: 1607-7938/hess/2006-10-101

European Geosciences Union

\title{
On the calculation of the topographic wetness index: evaluation of different methods based on field observations
}

\author{
R. Sørensen ${ }^{1}$, U. Zinko ${ }^{2}$, and J. Seibert ${ }^{3}$ \\ ${ }^{1}$ Department of Environmental Assessment, Swedish University of Agricultural Sciences, P.O. Box 7050, S-75007 Uppsala, \\ Sweden \\ ${ }^{2}$ Department of Ecology and Environmental Science, Umeå University, Uminova Science Park, S-90187 Umeå, Sweden \\ ${ }^{3}$ Department of Physical Geography and Quaternary Geology, Stockholm University, S-10691 Stockholm, Sweden
}

Received: 14 July 2005 - Published in Hydrology and Earth System Sciences Discussions: 31 August 2005

Revised: 9 September 2005 - Accepted: 12 January 2006 - Published: 15 February 2006

\begin{abstract}
The topographic wetness index (TWI, $\ln (a / \tan \beta))$, which combines local upslope contributing area and slope, is commonly used to quantify topographic control on hydrological processes. Methods of computing this index differ primarily in the way the upslope contributing area is calculated. In this study we compared a number of calculation methods for TWI and evaluated them in terms of their correlation with the following measured variables: vascular plant species richness, soil $\mathrm{pH}$, groundwater level, soil moisture, and a constructed wetness degree. The TWI was calculated by varying six parameters affecting the distribution of accumulated area among downslope cells and by varying the way the slope was calculated. All possible combinations of these parameters were calculated for two separate boreal forest sites in northern Sweden. We did not find a calculation method that performed best for all measured variables; rather the best methods seemed to be variable and site specific. However, we were able to identify some general characteristics of the best methods for different groups of measured variables. The results provide guiding principles for choosing the best method for estimating species richness, soil $\mathrm{pH}$, groundwater level, and soil moisture by the TWI derived from digital elevation models.
\end{abstract}

\section{Introduction}

Topography is a first-order control on spatial variation of hydrological conditions. It affects the spatial distribution of soil moisture, and groundwater flow often follows surface topography (Burt and Butcher, 1986; Seibert et al., 1997; Rodhe and Seibert, 1999; Zinko et al., 2005). Topographic indices have therefore been used to describe spatial soil moisture patterns (Burt and Butcher, 1986; Moore et al., 1991).

Correspondence to: R. S $ø$ rensen

(rasmus.sorensen@ma.slu.se)
The spatial distribution of groundwater levels influences soil processes and will in turn affect the properties of the soil (e.g. Zinko et al., 2005; Sariyildiz et al., 2005; Band et al., 1993; Florinsky et al., 2004; Whelan and Gandolfi, 2002).

The topographic wetness index (TWI) was developed by Beven and Kirkby (1979) within the runoff model TOPMODEL. It is defined as $\ln (a / \tan \beta)$ where $a$ is the local upslope area draining through a certain point per unit contour length and $\tan \beta$ is the local slope. The TWI has been used to study spatial scale effects on hydrological processes (Beven et al., 1988; Famiglietti and Wood, 1991; Sivapalan and Wood, 1987; Siviapalan et al., 1990) and to identify hydrological flow paths for geochemical modelling (Robson et al., 1992) as well as to characterize biological processes such as annual net primary production (White and Running, 1994), vegetation patterns (Moore et al., 1993; Zinko et al., 2005), and forest site quality (Holmgren, 1994a).

Topography affects not only soil moisture, but also indirectly affects soil pH (Högberg et al., 1990; Giesler et al., 1998). Soil moisture and $\mathrm{pH}$ are important variables that influence distribution (Giesler et al., 1998) and species richness of vascular plants (Zinko et al., 2005; Gough et al., 2000; Pärtel, 2002; Grubb, 1987) in Fennoscandian boreal forests. Because of the links between topography and plant species richness, the TWI has been useful for predicting the spatial distribution of vascular plant species richness in the Swedish boreal forest (Zinko, 2004). In these studies the TWI explained $52 \%$ of the variation in plant species richness for a site with relatively higher average soil $\mathrm{pH}$ (HP-site) and 30\% of the variation for a site with lower average soil $\mathrm{pH}$ (LP-site). In the same studies, TWI was also found to correlate well with depth to groundwater and soil $\mathrm{pH}$. (LP; groundwater: Spearman's rank correlation $r_{s}=0.58, P<0.001, n=46$; soil pH: $r_{s}=0.50, P<0.001, n=84$; HP: groundwater level: $r_{s}=0.71, P<0.001, n=45$; soil $\mathrm{pH}$ : $\left.r_{s}=0.71, P<0.001, n=55\right)$. 
The TWI is usually calculated from gridded elevation data. Different algorithms are used for these calculations; the main differences are the way the accumulated upslope area is routed downwards, how creeks are represented, and which measure of slope is used (Quinn et al., 1995; Wolock and McCabe, 1995; Tarboton, 1997; Güntner et al., 2004). New algorithms have been evaluated primarily in terms of comparisons with other algorithms (e.g. Quinn, 1991; Holmgren, 1994a; Tarboton, 1997) or in terms of theoretical geometric correctness (Pan et al., 2004). Only a few studies have evaluated the TWI computation algorithms using spatially distributed field measurements. Güntner et al. (2004) compared different algorithms and modifications of the TWI with the spatial pattern of saturated areas. They concluded that the ability of the TWI to predict observed patterns of saturated areas was sensitive to the algorithms used for calculating upslope contributing area and slope gradient. Kim and Lee (2004) evaluated different calculation methods based on their ability to predict the observed stream network and found that a modification of the multidirectional flow accumulation algorithm suggested by Quinn et al. (1991) was needed to solve the problem of flow dispersion overestimation in near-stream cells.

In this study, we asked whether or not the correlation between TWI and a number of variables for which a correlation could be expected depends on the method used to calculate the TWI. Spatially distributed field observations of plant species richness, soil $\mathrm{pH}$, groundwater level, and soil moisture were used to evaluate the different methods. Initial results indicated that different methods might provide differing results. Therefore, we sought to determine whether it was possible to find one single TWI computation method for estimating different field variables in boreal forest landscapes. We used data from Zinko (2004) for two boreal forest sites in northern Sweden that differed in average soil pH. In contrast to previous studies on the relationship between plant species richness and TWI (Zinko et al., 2005; Zinko, 2004), we started this study with the assumption that there actually should be a correlation between TWI and the different field variables. Therefore, a suitable computation algorithm for TWI should provide this correlation and the highest correlation coefficients would indicate the most suitable computation algorithm. Our study was restricted to calculations of TWI based on raster elevation data $(20 \times 20 \mathrm{~m}$ resolution). We also restricted the analysis to point-to-point comparisons because our field observations were not suitable for other comparison methods such as those described by Grayson et al. (2002) or Güntner et al. (2004).

The main questions we addressed for this paper were: (1) Do different calculation methods and modifications of TWI give different results in terms of correlation with measured variables of hydrology, soil chemistry, and vegetation? (2) Which combinations of calculation methods and parameters provide the most accurate results? (3) Is there one general method for TWI computation that provides near-optimal cor- relations for different areas and different measured variables of hydrology, soil chemistry, and vegetation?

\section{Material and methods}

\subsection{TWI calculation methods and modifications}

The raster DEM with a grid size of 20 by $20 \mathrm{~m}$ had been derived from aerial photography using a Zeiss PlaniComp analytic stereo instrument (accuracy of $\pm 0.7 \mathrm{~m}$ ). When calculating TWI from the DEM, different algorithms and modifications of the original "TOPMODEL" index (Beven and Kirkby, 1979) can be used. The variants of TWI differ in the ways that the upslope area $a$, creek cell representation, and slope are computed. The different calculation methods we tested are listed below.

\subsubsection{Upslope area}

Calculation of upslope area depends on the way the accumulated area of upstream cells is routed to downstream cells. Traditionally, the area from a cell has been transferred in the steepest downslope direction to one of the eight neighbouring cells. Quinn et al. (1991) introduced a multidirectional flow algorithm that allowed the area from one cell to be distributed among all neighbouring downslope cells, weighted according to the respective slopes. The distribution of area to each downslope cell was based on slope according to the term $\mathrm{F}_{i}=\tan \beta_{i} / \Sigma \tan \beta_{i}$. Quinn's multiple flow algorithm more accurately predicted flow paths in the upper part of the catchment while the single directional flow algorithm had higher predictive power in the lower parts (Quinn et al., 1991).

Holmgren (1994b) extended Quinn et al.'s (1991) distribution function by introducing an exponent $h$ that controls the distribution among downslope directions according to $\tan \beta_{i}^{h} / \Sigma \tan \beta_{i}^{h}$, where $0 \leq h \leq \infty$. A high exponent $(h)$ means that more accumulated area will be distributed in the steepest direction, i.e. more similar to single directional flow. The lower the exponent the more equally the flow will be distributed among the downslope cells (for a more detailed description see Holmgren, 1994b, or Quinn et al., 1995). This exponent can thus be seen as a parameter that causes a gradual transition from single directional flow (infinite $h$; in practice values above $\sim 25)$ to multidirectional flow $(h=1)$.

In the usual single-direction algorithm, the steepest direction into which the accumulated area is routed is restricted to the eight cardinal and diagonal directions. An alternative was proposed by Tarboton (1997), who calculated the steepest downslope direction based on triangular facets that allowed the steepest direction to be routed in any direction rather than being restricted to the eight cardinal and diagonal directions. The accumulated area is then routed to the two cardinal and diagonal directions that are closest to the steepest direction weighted according to their distance from 
this direction. This method was further developed by allowing multiple flow directions (Seibert, unpubl. manuscript). Around the midpoint, $\mathrm{M}$, of any pixel, eight planar triangular facets were constructed with the midpoints, $\mathrm{P}_{1}$ and $\mathrm{P}_{2}$, of two adjacent neighbouring pixels. The slope direction of this plane (determined by $\mathrm{M}, \mathrm{P}_{1}$, and $\mathrm{P}_{2}$ ) was computed for each facet. If the steepest slope direction was outside the $45^{\circ}$ ( $\pi / 4$ radian) angle range of the particular triangular facet (i.e., not between the vectors pointing from $\mathrm{M}$ towards $\mathrm{P}_{1}$ and $\mathrm{P}_{2}$, respectively), the direction with the steeper gradient of the two directions towards $\mathrm{P}_{1}$ or $\mathrm{P}_{2}$, was used as the steepest direction. After computing the steepest direction for all eight triangular facets, those directions that had a steeper gradient than both of their adjacent facets were identified. These directions were interpreted as local outflows and the accumulated area was distributed among these directions. Similar to Quinn's multidirectional flow algorithm the $h$ exponent was used to control the weighting of the different directions according to their respective slopes. We tested both Tarboton's and Quinn's approach with different values for the exponent, $h$, as mentioned above. Both of the algorithms were tested with seven values for $h: 0.5,1,2,4,8,16$, and 32 , for a total of 14 different combinations of flow distribution methods.

\subsubsection{Creek representation}

The basic assumptions of the TWI do not hold when there is a creek and, thus, creeks need to be considered explicitly. We assumed that creeks began when the accumulated area exceeded a certain creek initiation threshold area (cta). The accumulated area of a "creek cell" is usually routed downslope as "creek area" and not considered in the calculation of $a$ in downslope cells. However, a key question is if the area below cta should be routed downwards and contribute to $a$ (i.e., only the area exceeding cta is treated as creek area) or if all accumulated area should be routed downwards as creek area. We tested both variants (called cta-down) and 8 values for cta: $2.5,5,10,15,20,30,40$, and 50 ha.

\subsubsection{Slope}

The local slope $\tan \beta$ might not always be a good representation of the groundwater table hydraulic gradient because downslope topography more than one cell distant is not considered. A new slope term, $\tan \alpha_{d}$ was introduced by Hjerdt et al. (2004) in response to this issue. In contrast to $\tan \beta$, which only considers the cell of interest and its neighbours, $\tan \alpha_{d}$ is defined as the slope to the closest point that is $d$ meters below the cell of interest. Both slope estimates give similar results for small values of $d$, but the results differ for larger values of $d$ (Hjerdt et al., 2004). The distance to this point can be computed as either beeline distance or distance along the flow path (i.e., always following the steepest downslope directions). In the following text this parameter is called slope distance. We tested both $\tan \beta$ and $\tan \alpha_{d}$, vary- ing the latter with different vertical distances $d: 2,5,10,15$, and $20 \mathrm{~m}$ (i.e., in total 6 slope variants). Both beeline and flow path distance were tested.

In summary, combinations of three binary (flow distribution, cta-down, slope distance) and three continuous ( $h, c t a$, d) calculation parameters were tested. For the continuous parameters we tested six to eight different values. A total of $2688(=2 \cdot 2 \cdot 2 \cdot 7 \cdot 8 \cdot 6)$ different TWI values were computed for each of the two forest sites.

We treated cells without any adjacent downslope cell, i.e., depressions, as real topographic features and not as errors in the elevation data. Therefore, instead of "filling" these depressions before the index was calculated, we continued the search for downslope cells using all cells located 2, $3, \ldots$ cells away until the nearest downslope cell was found; the area was routed to this/these cell(s) (Rodhe and Seibert, 1999). An initial test indicated that filling the sinks would not have significantly influenced the results of this study.

We did not compare the TWI values directly to the observed field data but used the mean value of a $3 \times 3$ cell window around the particular cell to minimize the effect of erroneously assigning a sample site to the wrong cell in the DEM.

\subsection{Study sites and field measurements}

The study was performed in two separate $25-\mathrm{km}^{2}$ boreal forest sites in northern Sweden: one site with low average soil pH (LP) in Åmsele, Västerbotten county $\left(64^{\circ} 33^{\prime} \mathrm{N}\right.$, $\left.19^{\circ} 35^{\prime} \mathrm{E}\right)$, and one site with high average soil $\mathrm{pH}$ (HP) $240 \mathrm{~km}$ to the southwest in Kälarne, Jämtland county $\left(62^{\circ} 59^{\prime} \mathrm{N}, 16^{\circ} 01^{\prime} \mathrm{E}\right)$. The elevations of both sites vary between 220 and $400 \mathrm{~m}$ a.s.l. The bedrock is mainly granitic and the soil consists of glacial till with peat cover in the depressions. Yearly precipitation is about $600 \mathrm{~mm}$ at both sites. Mean temperature in January is $-13^{\circ} \mathrm{C}$ and $-10^{\circ} \mathrm{C}$ for the LP and HP sites respectively, and in July is $+14^{\circ} \mathrm{C}$ for both sites (Raab and Vedin, 1995). Vegetation at both sites is dominated by boreal forest composed mainly of Pinus sylvestris and Picea abies; intensive silviculture has been conducted for over 50 years in these forests. The studied areas therefore include semi-natural forest, clear-cuts, and plantations of native and exotic (Pinus contorta, Abies sp.) tree species. For a more detailed description of the study sites see Zinko (2004). Study plots of $200 \mathrm{~m}^{2}$ were distributed to the centre of the $400 \mathrm{~m}^{2}$ grids of the digital elevation model used for calculating the topographical index. The study plots ( 88 plots in the LP site and 56 plots in the HP site) were randomly distributed within each site, but constrained so that the number of samples for different classes of TWI values was equal (i.e., high TWI values were sampled more frequently than would correspond to their occurrence in the landscape). The plots were located in the field by a GPS receiver. Marshlands without trees, lakes, and streams were not included in this study. 


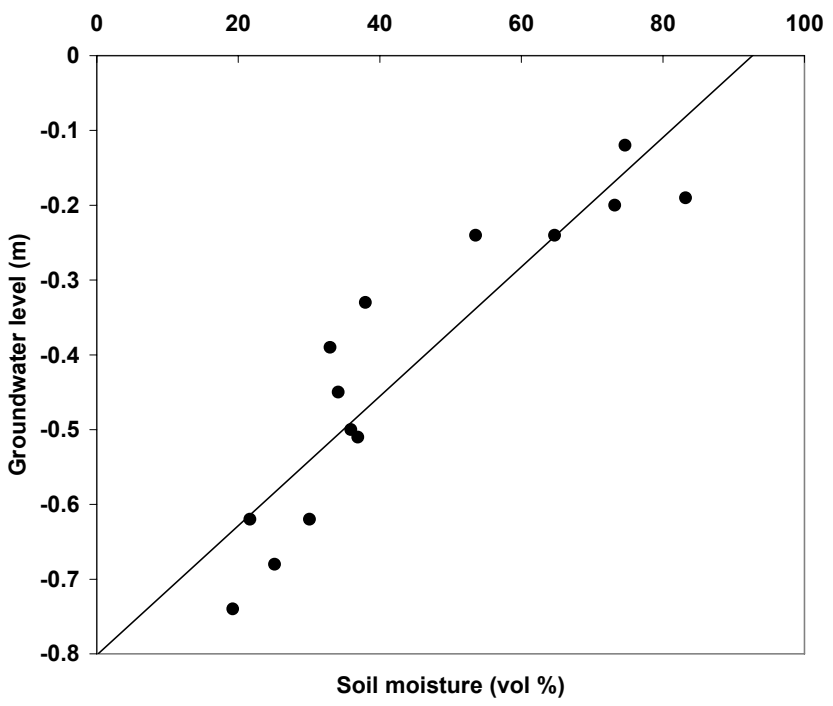

Fig. 1. Relationship between soil moisture (measured with TDR) and groundwater levels at the HP site in July 2002. Observations of both variables were available for 14 plots $\left(r^{2}=0.823, P>0.001\right.$, $n=14)$.

We catalogued all vascular plant species at the LP site in July 1999 and in July 2002 at the HP site. Soil sampling was conducted in 2002 and 2003 at the HP and LP sites, respectively. Cores of 2.5 (LP) and 5 (HP) $\mathrm{cm}$ diameter and up to $30 \mathrm{~cm}$ long were collected for soil $\mathrm{pH}$ measurement from the O-horizons at eight evenly distributed locations within $2 \mathrm{~m}$ of the plot centre. The eight soil samples were bulked to one single sample, air-dried, and analysed for soil $\mathrm{pH}(\mathrm{H} 2 \mathrm{O}$, $1: 25$, soil:solution mass ratio).

Polyethylene tubes with an inner diameter of $9 \mathrm{~mm}$ were installed to a depth of $0.7 \mathrm{~m}$ as close as possible to the centre of the plots to measure ground water levels. At one plot in each study site, the presence of bedrock and boulders made it impossible to insert a tube. For the same reason not all tubes were inserted to $0.7 \mathrm{~m}$. We excluded all plots at which groundwater levels were never recorded (38 plots in the LP site and 10 plots in the HP site). Groundwater levels were measured four times (once a month) between June and September 2001 at the LP site and twice during 2002 (July and October) at the HP site. We used the mean of the four groundwater level measurements at the LP site for the statistical analysis. Since summer and fall 2002 were dry, with groundwater levels below $0.7 \mathrm{~m}$ in many HP plots, we used only one occasion (October) of groundwater level measurements. For the wells for which groundwater levels could be observed in both months the levels were clearly correlated $(r=0.69)$.

At the HP site, soil moisture in the upper $15 \mathrm{~cm}$ was measured with a Time Domain Reflectometry (TDR) instrument (TRIME FM3 manufactured by IMKO, Germany). The factory-set calibration curve that translates the dielectric con- stant of the soil into soil water content was used for all measurements. The soil water content of a plot was calculated as the mean value of the eight measurements, which were taken at about $2 \mathrm{~m}$ distance from the center towards all cardinal and diagonal directions. At soil water contents above $\sim 50 \%$, the measurements became unreliable and unrealistic soil water contents of up to $80-100 \%$ were returned for wet soils. While these values obviously are not correct, it was assumed that they still could be used as a relative measure to compare the wetness in the different plots. Very wet plots, in which the ground water was at or close to the ground surface and where the TDR measurements gave values of $100 \%$ for most points, were excluded from further soil moisture analyses. TDR measurements were performed in July and October 2002. Both measurements were highly correlated $(r=0.90)$ and only the July measurements were used in this paper. Soil moisture and groundwater levels were measured for all plots during a 2-3 day period without precipitation so that the conditions could be assumed to be constant during the measurement period.

For the HP site, the July groundwater and soil moisture measurements were combined into a parameter called "degree of wetness", which allowed ranking of all locations according to soil moisture and groundwater observations. This was motivated by the fact that groundwater observations were not available for dry locations where the levels were more than $0.7 \mathrm{~m}$ below the surface; whereas the TDR measured soil moisture was unreliable for wet locations. The "degree of wetness" is an approach to combine soil moisture and groundwater data into one data series. In this way the two methods complemented each other and allowed ranking of all plots according to a single wetness variable. We performed a linear least square regression with groundwater level as the dependent variable and soil moisture as the predictor. Groundwater level could then be expressed as a function of soil moisture (Fig. 1). For plots $(n=22)$ where only soil moisture content was measured in July a value based on this function was estimated. If only groundwater level was measured there was no modification $(n=11)$. If both TDR and groundwater level were measured, the average of estimated and measured groundwater level was used $(n=14)$, i.e., both types of hydrological data were represented and got the same weight. If neither moisture nor ground water level was measured, the location was excluded from the analysis $(n=9)$. The degree of wetness computed in this way was then used to rank the plots according to wetness conditions and these ranks were used for the calculation of Spearman's rank correlations. While the relationship between soil moisture and groundwater is not linear we suppose that a linear approximation is acceptable within the ranges of our measurements for the ranking as described above.

The different variables obviously were correlated to some degree. The correlation coefficients varied from 0.28 to 0.87 (Table 1). With a weak correlation it is possible that different methods provide best results, although even with low 
correlations one single method could be best in all cases. In general, the correlation matrix suggests two groups of variables. Correlations between plant species richness and soil $\mathrm{pH}$ as well as groundwater levels and soil moisture were higher than correlations across these two groups of variables.

\subsection{Data analysis}

All correlation coefficients between the 2688 different TWI values and the measured variables (plant species richness, soil $\mathrm{pH}$, groundwater level, soil moisture, and wetness degree (for the HP site)) for each site were calculated using Spearman's rank correlation. The results were examined in three ways:

(1) The highest correlation coefficient (HC) between each measured variable and each of the parameter values was identified. For each measured variable this was done by keeping one parameter fixed to a certain value but allowing the other parameters to vary. The variability of the $\mathrm{HC}$ within a parameter was then analysed.

(2) The 10\% methods (best-10\%) resulting in the highest correlations between TWI and measured variables were selected and distribution functions were compiled for each parameter. We also computed the overlap of the best-10\% sets between the two study sites as well as for the different measured variables within each study site. The overlap was computed as the ratio between the number of methods found in both best- $10 \%$ sets and the total number of methods in a best-10\% set (269).

(3) Finally, we determined which calculation methods were most suitable for more than one variable. For each set of correlations between each measured variable and parameter value the differences $(\Delta \mathrm{C})$ between the highest correlation coefficient and all the other correlation coefficients were computed. The measured variables were divided into different groups and the mean differences $\overline{\Delta \mathrm{C}}$ for all variables within a group were calculated. The calculation method with the lowest $\overline{\Delta \mathrm{C}}$ was considered the most suitable TWI calculation method for this particular group of measured variables. The groups used in this analysis were: (i) all variables from both sites (to obtain an overall best calculation method), (ii) all parameters from the HP site, (iii) all variables from the LP site, (iv) different groups of the measured variables.

The first approach showed the best calculation method for each single measured variable alone, whereas the second approach provided information on how likely a good correlation was depending on a certain value for one single parameter. The two approaches, $\mathrm{HC}$ and best- $10 \%$, were used together to decide on the best methods for each measured variable and were expected to return similar results. The third approach gave a general perception of the processes influencing the groups of measured parameters.

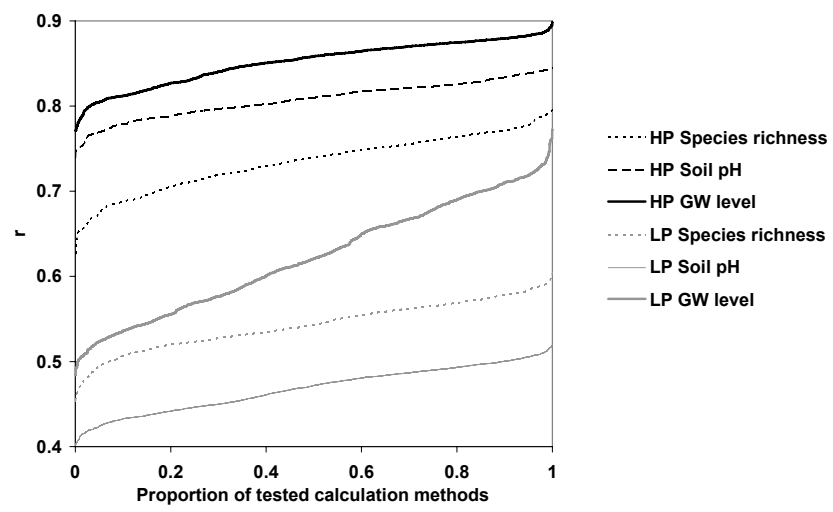

Fig. 2. Accumulated distributions of Spearman rank correlation coefficients, increasing from the poorest correlation (left side) to the best correlations (right side), obtained by using the 2688 different TWI values.

\section{Results}

The correlations between TWI values and measured variables varied considerably between the different calculation methods. The Spearman rank correlation between TWI and soil $\mathrm{pH}$, for instance, varied between 0.40 and 0.52 for the LP site and between 0.74 and 0.84 for the HP site (Fig. 2). Among all variables at both sites the least accurate method gave correlations between 0.11 and 0.29 units lower than the best of the tested methods.

\subsection{Single measured variables}

Different calculation methods yielded the strongest correlations for the different single measured variables at the two study sites. Below we summarize the results for each parameter (see also Fig. 3 and Table 2).

\subsubsection{Flow distribution}

The modification of Tarboton's approach was superior for calculation of flow distribution (Table 2), except for $\mathrm{pH}$ and groundwater level at the HP site, where Quinn's method achieved a higher portion among the best-10\% methods.

\subsection{2 h_exponent}

The $h$ values of the best methods were evenly distributed for species richness for the LP site. For $\mathrm{pH}$, higher $h$ values dominated the best- $10 \%$, while lower $h$ values gave better results for groundwater. The best of the highest correlations (HCs) for species richness and soil $\mathrm{pH}$ were similar among all parameter values, whereas the best $\mathrm{HC}$ for groundwater was with low $h$ values (Fig. 3a). A slightly different pattern was observed at the HP site. For plant species richness and groundwater level, $h=0.5$ had the best- $10 \%$ (Fig. 3d). A low $h(h=2)$ also performed best for soil moisture. For 
Table 1. Pearson correlation coefficients, $r$, among the measured variables for the HP-site (Table 1a) and for the LP-site (Table 1b).

\begin{tabular}{llllll} 
1a. & & & & & \\
\hline HP - Kälarna & $\begin{array}{l}\text { Spec } \\
\text { rich }\end{array}$ & pH & $\begin{array}{l}\text { GW } \\
\text { level }\end{array}$ & TDR & $\begin{array}{l}\text { Wetness } \\
\text { degree }\end{array}$ \\
\hline Spec rich & 1 & & & & \\
pH & 0.87 & 1 & & & \\
GW level & 0.48 & 0.66 & 1 & & \\
TDR & 0.41 & 0.61 & 0.86 & 1 & \\
Wetness degree & 0.62 & 0.78 & 0.96 & 0.95 & 1 \\
\hline 1b. & & & & & \\
\hline LP - Åmsele & Spec & pH & GW & & \\
& rich & & level & & \\
\hline Spec rich & 1 & & & & \\
pH & 0.62 & 1 & & \\
GW level & 0.32 & 0.28 & 1 & & \\
\hline
\end{tabular}

soil $\mathrm{pH}$ and wetness degree the $h=8$ and 16 , respectively, had slightly better best-10\%. The best HCs were found using the three lowest h-exponent values $(h=0.5,1$, or 2$)$ for plant species richness, soil $\mathrm{pH}$, and groundwater level while the highest value $(h=32)$ gave the highest HCs for soil moisture and wetness degree (Fig. 3d).

\subsection{3 cta}

At the LP site, high cta values had the highest portion of the best-10\% for species richness, whereas for $\mathrm{pH}$ and groundwater level, lower cta values had the highest portion (Fig. 3b). This also applied for the HCs. For the HP site, the groundwater level followed the same pattern, but for the rest of the measured variables the best- $10 \%$ were evenly distributed and the HCs were similar (Fig. 3e).

\subsection{4 cta-down}

The decision as to whether or not the area corresponding to cta was routed downslope as groundwater flow did not influence the correlations. In both sites the portion of the best$10 \%$ was equally distributed between the two options (not shown).

\subsubsection{Slope}

For the LP site, $\tan \beta$ or $\tan \alpha_{2}$ had the largest portion of the best-10\% for species richness, soil $\mathrm{pH}$, and groundwater level (Fig. 3c). The highest HC was found when using $\tan \beta$ for all three measured variables. At the HP site $\tan \alpha_{20}$ gave best results both with respect to best-10\% and HC for soil $\mathrm{pH}$ and species richness (Fig. 3f). According to the best-
$10 \%$ and $\mathrm{HC}, \tan \alpha_{2}$ was found to be best for groundwater, whereas $\tan \beta$ was best for soil moisture and wetness degree.

\subsubsection{Slope-distance}

The downslope index computed with the beeline distance performed best for both plant species richness and soil $\mathrm{pH}$ at both sites (Table 2). In contrast, the distance following the flow path gave best results for the groundwater levels at both sites and soil moisture at the HP site (Table 2). The slope distance method did not affect the correlations with wetness degree at the HP site.

The large variation in best parameter values for the different measured variables indicates that there is no single best method. In general, there was also a relatively small overlap between the best-10\% methods for the different measured variables and study sites (Table 3 ). At the HP site, there was significant overlap between the best methods for plant species number and soil $\mathrm{pH}$ as well as among the hydrological variables (although one has to consider that wetness degree was calculated from groundwater level and moisture). No overlap at all between any of the hydrological variables and species richness or soil $\mathrm{pH}$ was found at the HP site. There was significant overlap at the LP site among all three parameters (Table 3). There was overlap among the hydrological parameters and between the $\mathrm{pH}$-methods for both sites together. There was also significant overlap between the $\mathrm{pH}$ at the HP site and the species richness and the $\mathrm{pH}$ at the LP site, but not between the species richness at both sites. However the species richness at the LP site overlapped with the soil moisture at the HP site.

\subsection{Grouped measured variables}

The overall best calculation method, evaluated by the portion among the best- $10 \%$, was found when using the modification of Tarboton's flow distribution, low values of $h(h=1-2)$, the $\tan \beta$ slope, and cta values of $15 \mathrm{ha}$. Slope distance did not have any influence on the correlations (Fig. 4, Table 4), nor did the cta-down (not shown).

We identified two groups of measured variables that each had generally similar best-10\% distributions, with plant species richness and soil $\mathrm{pH}$ in one group, and groundwater level, soil moisture, and wetness degree in the other. The calculation parameters performing best for the first group were Quinn's flow distribution method, $h$ value of $2-8, \tan \alpha_{15}$ slope and beeline slope distance, and cta values of 15-20 ha (Fig. 4, Table 4). For the group of hydrological variables, the best results were obtained with Tarboton's flow distribution, $h$ value of $1-2$, cta value of $10-20 \mathrm{ha}, \tan \beta$ slope, and flow path slope distance (Fig. 4, Table 4). The parameter cta-down did not have any influence on the correlations (not shown).

Grouping the variables by study site resulted in best performance for Tarboton's flow distribution and $\tan \beta$ slope for all measured variables in the HP site. The other parameters 
LP
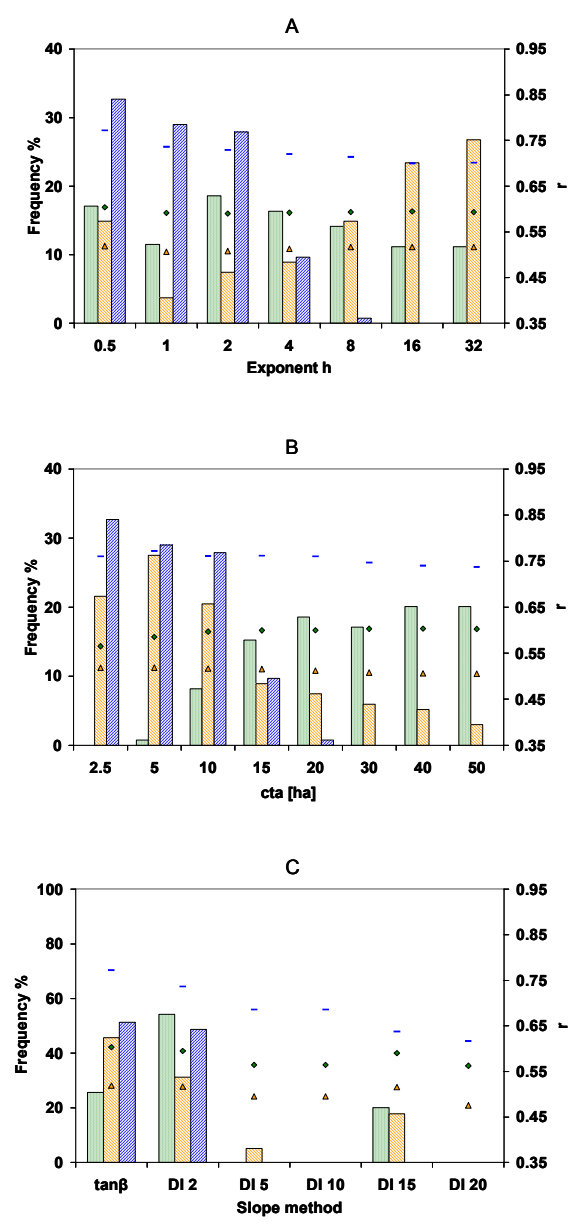

HP
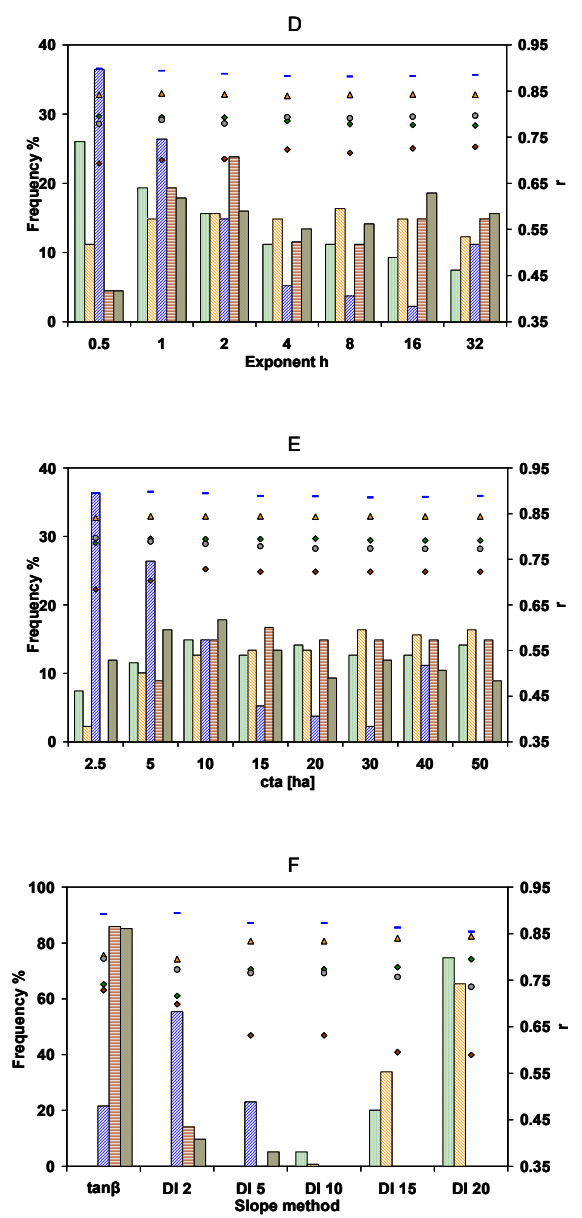

Species richness

$\Delta$ Soil pH

- GW levels

- Soil moisture

- Wetness degree

Fig. 3. Distributions for each measured variable of the best $10 \%$ calculation methods (bars) among different values of the exponent $h$, the slope method (including different values for the $\mathrm{d}$ in the downslope index), and the creek initiation area, cta. The highest correlation coefficients (HC) obtained using a certain parameter value are shown by symbols. The figures (a-f) show the distributions for the three different parameters in the two study areas: (a) $h$ in the LP site. (b) cta in the LP site. (c) slope in the LP site. (d) $h$ in the HP site. (e) cta in the HP site. (f) slope in the HP site. Note the different scale on the y-axis for the slope method.

exhibited no significant influence on correlations for this site, but $h$ values of 0.5 and $c t a$ values of 2.5-5 gave lower correlations (Fig. 4, Table 4). In the LP site Tarboton's flow distribution, low values of $h(0.5-2)$, cta values of 10-20, $\tan \alpha_{d 2}$ slope, and the beeline distance yielded the best results (Fig. 4, Table 4). Cta-down did not have any effect on the results in any of the sites (not shown).
The best calculation methods when grouping the measured variables according to type or site resulted in correlation coefficients between the overall best calculation method and the best calculation method for each single measured variable (Table 5). 

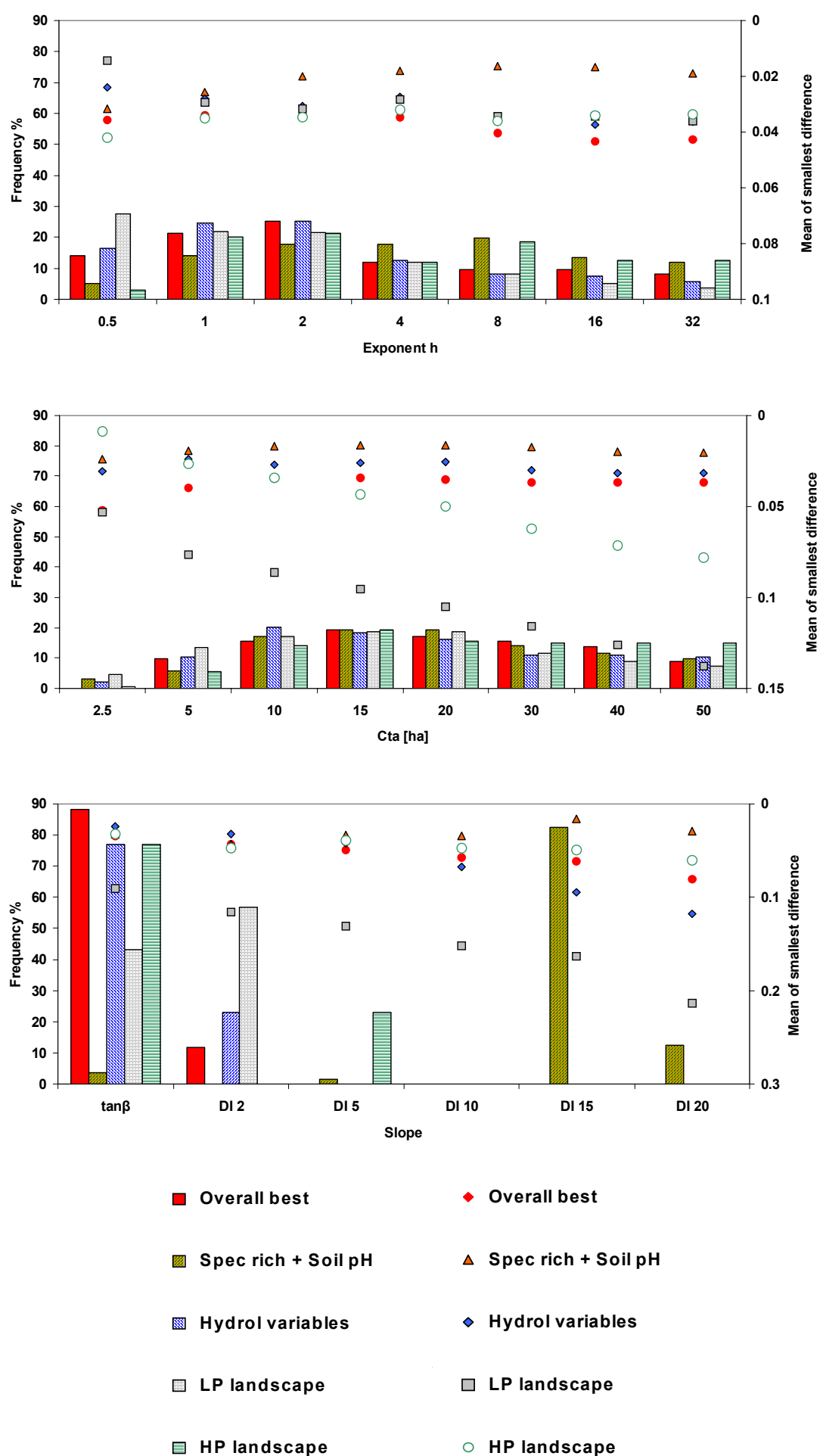

Overall best

$\Delta$ Spec rich + Soil pH

$\diamond$ Hydrol variables

$\square$ LP landscape

HP landscape

Fig. 4. Distribution of the best $10 \%$ calculation methods (bars) among different values of the exponent $h$, the slope method (including different values for the $\mathrm{d}$ in the downslope index), and the creek initiation area, cta, for different groups of measured variables. The symbols show how much correlation coefficients decrease when using the best method for a group instead of the best method for the individual variables. This was expressed as the mean of the differences between the highest correlation coefficients obtained for each individual variable and the highest correlation coefficients, which were obtained for the entire group for a certain parameter value. 
Table 2. Distribution of the best $10 \%$ of all tested calculation methods (using different measured variables) for flow distribution and slope distance respectively. Note that there were only two options for each of these two parameters. As both options were tested equally often in all cases, the deviation from a 50-50 distribution indicates how important a certain choice is. The highest Spearman's rank correlation coefficients, $r_{s}$, which were obtained with a certain method, are given in brackets.

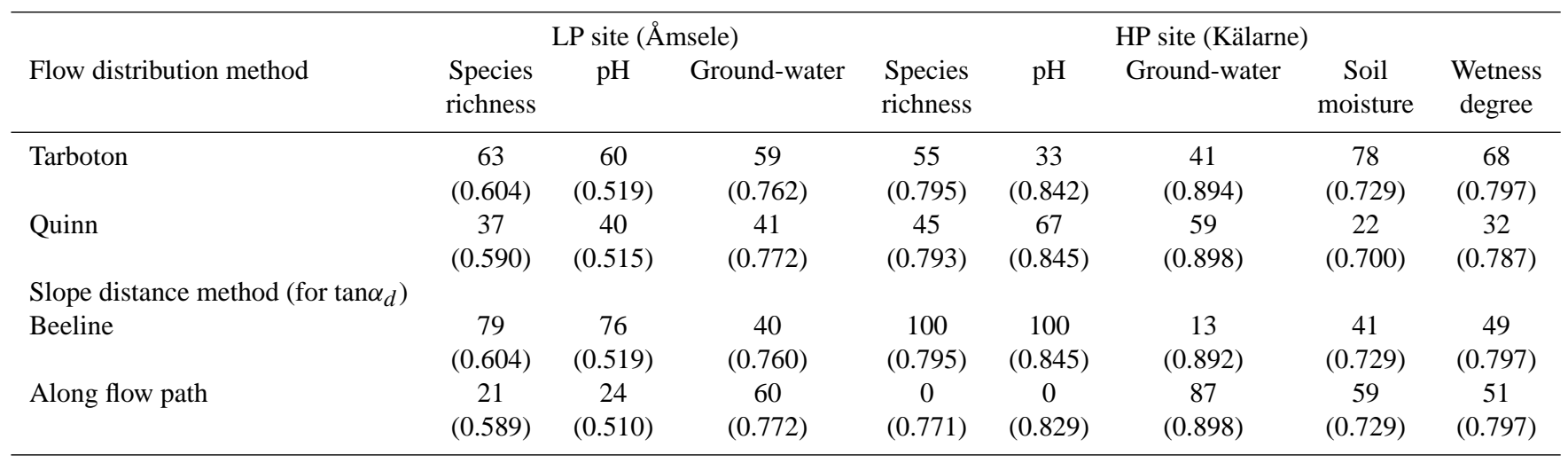

Table 3. Overlapping between the best $10 \%$ calculation methods for the different measured variables. The overlap was computed as the ratio between the number of methods found in both best-10\% sets (of the measured variables to be compared) and the total number of methods in a best-10\% set $(n=269)$. For random drawings the overlapping ratio would be smaller than 0.071 with a probability of 0.05 and higher than 0.127 with a probability of 0.95 .

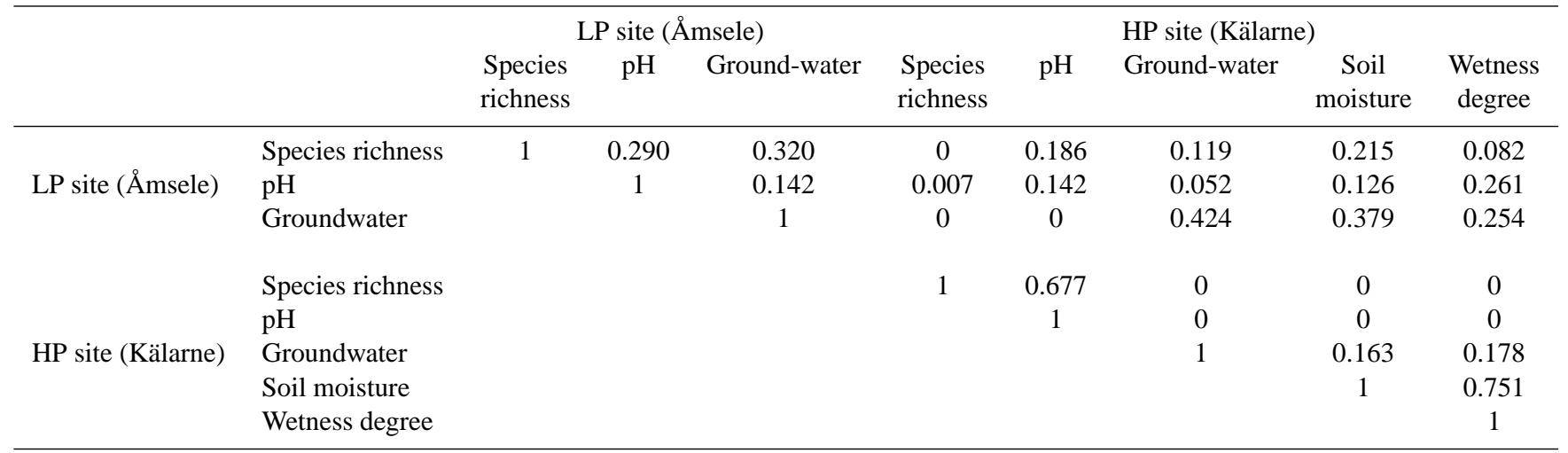

\section{Discussion}

Our results demonstrate that different methods of calculating the TWI indeed produce a high variation in correlation strengths between the various TWI values and the different measured variables. There was not one single method that was optimal for all variables and study sites. Overall, the overlap of the best- $10 \%$ between either measured variables or study sites was rather small (Table 3). However, general characteristics for methods yielding the best-10\% could be observed for certain groups of variables.

The correlation coefficients decreased with the generality of the calculation method. The best overall calculation method did not yield as strong correlations as the best calcu- lation methods for each single measured variable. However, the latter calculation methods were only optimal for a particular variable and study site and are thus of more limited general applicability.

In our study, the modification of Tarboton's flow distribution method was in general superior to Quinn's distribution method. This was expected, since Quinn's method tends to overestimate flow dispersion and braiding, especially in nearstream areas (Kim and Lee, 2004). Pan et al. (2004) found the multiple flow direction to be geometrically more accurate than the single flow direction algorithm in idealized DEMs. Our empirical study also found that the multiple directional flow algorithms were superior to the single-directional algorithm in both Quinn's and Tarboton's methods. However, 
Table 4. Distribution of the best $10 \%$ of all tested calculation methods (using different groups of measured variables) for flow distribution and slope distance respectively. Note that there were only two options for each of these two parameters. As both options were tested equally often in all cases, the deviation from a 50-50 distribution indicates how important a certain choice is. The mean of the difference between the very best correlation coefficient for each measured parameter and the group wise best correlation coefficient are given in brackets.

\begin{tabular}{|c|c|c|c|c|c|}
\hline & $\begin{array}{l}\text { Species } \\
\text { richness } \\
\text { and } \mathrm{pH}\end{array}$ & $\begin{array}{c}\text { Groundwater, } \\
\text { soil moisture } \\
\text { and wetness } \\
\text { degree }\end{array}$ & $\begin{array}{c}\text { LP } \\
(\text { Åmsele) } \\
\text { site }\end{array}$ & $\begin{array}{c}\text { HP } \\
\text { (Kälarne) } \\
\text { site }\end{array}$ & All \\
\hline \multicolumn{6}{|c|}{ Flow distribution method } \\
\hline Tarboton & $\begin{array}{c}41 \\
(0.093)\end{array}$ & $\begin{array}{c}71 \\
(0.181)\end{array}$ & $\begin{array}{c}87 \\
(0.154)\end{array}$ & $\begin{array}{c}74 \\
(0.114)\end{array}$ & $\begin{array}{c}77 \\
(0.125)\end{array}$ \\
\hline Quinn & $\begin{array}{c}59 \\
(0.096)\end{array}$ & $\begin{array}{c}29 \\
(0.168)\end{array}$ & $\begin{array}{c}13 \\
(0.152)\end{array}$ & $\begin{array}{c}26 \\
(0.112)\end{array}$ & $\begin{array}{c}23 \\
(0.123)\end{array}$ \\
\hline \multicolumn{6}{|c|}{ Slope distance method (for $\tan \alpha_{d}$ ) } \\
\hline Beeline & $\begin{array}{c}91 \\
(0.084)\end{array}$ & $\begin{array}{c}37 \\
(0.181)\end{array}$ & $\begin{array}{c}58 \\
(0.154)\end{array}$ & $\begin{array}{c}52 \\
(0.104)\end{array}$ & $\begin{array}{c}48 \\
(0.121)\end{array}$ \\
\hline Along flow path & $\begin{array}{c}9 \\
(0.096)\end{array}$ & $\begin{array}{c}63 \\
(0.169)\end{array}$ & $\begin{array}{c}42 \\
(0.149)\end{array}$ & $\begin{array}{c}48 \\
(0.114)\end{array}$ & $\begin{array}{c}52 \\
(0.125)\end{array}$ \\
\hline
\end{tabular}

Table 5. Best Spearman rank correlation coefficients obtained for the single measured variables at each site and for different groups of variables. Correlation coefficients for correlations where the particular variable is included in the respective group are in bold.

\begin{tabular}{|c|c|c|c|c|c|c|}
\hline & \multirow[b]{2}{*}{$\begin{array}{l}\text { Best possible } \\
\text { correlation for } \\
\text { each variable }\end{array}$} & \multirow[b]{2}{*}{$\begin{array}{c}\text { Species richness } \\
\text { and } \mathrm{pH}\end{array}$} & \multicolumn{3}{|c|}{ Best correlation for groups of variables } & \multirow[b]{2}{*}{ All } \\
\hline & & & $\begin{array}{c}\text { Groundwater, soil } \\
\text { moisture and } \\
\text { wetness degree }\end{array}$ & $\begin{array}{l}\text { LP site } \\
\text { (Åmsele) }\end{array}$ & $\begin{array}{l}\text { HP site } \\
\text { (Kälarne) }\end{array}$ & \\
\hline \multicolumn{7}{|l|}{ LP site (Åmsele) } \\
\hline Species richness & 0.604 & 0.587 & 0.556 & 0.597 & 0.570 & 0.580 \\
\hline $\mathrm{pH}$ & 0.519 & 0.505 & 0.492 & 0.513 & 0.497 & 0.498 \\
\hline Groundwater & 0.772 & 0.582 & 0.772 & 0.743 & 0.711 & 0.722 \\
\hline \multicolumn{7}{|l|}{ HP site (Kälarne) } \\
\hline Species richness & 0.795 & 0.765 & 0.667 & 0.716 & 0.730 & 0.739 \\
\hline $\mathrm{pH}$ & 0.845 & 0.840 & 0.757 & 0.795 & 0.798 & 0.802 \\
\hline Groundwater & 0.898 & 0.835 & 0.886 & 0.872 & 0.862 & 0.871 \\
\hline Soil moisture & 0.729 & 0.582 & 0.676 & 0.674 & 0.723 & 0.702 \\
\hline Wetness degree & 0.797 & 0.721 & 0.765 & 0.746 & 0.792 & 0.772 \\
\hline
\end{tabular}

optimal values for $h$ were larger than one in some cases, indicating that the usual multidirectional flow algorithm might sometimes result in too large a spreading of the accumulated area. Holmgren (1994b) suggests a value of $h$ between 4 and 6 irrespective of DEM resolution. In our study the best correlations for the hydrological variables were mainly found with lower values of $h(0.5-2)$. The value of $h$ could depend on the steepness in the studied landscape. Our results combined with those of Güntner et al. (2004), who found $h$ values of 810 to be most suitable in a mountainous catchment, suggest that $h$ might decrease when going from mountainous (with steeper slopes) to hilly areas.

The best-10\% differed in terms of slope calculation between the two groups of measured variables. For plant species richness and soil $\mathrm{pH}$, a higher slope distance $\left(\tan \alpha_{d 15}\right)$ and the beeline distance should be used, while for the hydrological variables best results were obtained with $\tan \beta$ slope and slope distance calculated along the flow path. The difference in $d$ indicates that downslope drainage conditions are more important for the plant species richness and soil $\mathrm{pH}$ than for groundwater level, soil moisture, and wetness degree. A possible explanation is that local slope influences the hydrological variables, while larger geomorphologic features are more important for species richness of vascular plants and soil $\mathrm{pH}$. For example, a site on a plateau with relatively small upstream area but a low slope can be quite moist but have low soil $\mathrm{pH}$ and plant species richness. A higher value of $d$ gives information about the downslope 
conditions, which can indicate where along a slope the site is situated. A gentle slope would be found in the lower parts of a hill, while a steeper slope would indicate that the point is situated in a recharge area. Groundwater recharge and discharge areas differ considerably in terms of soil $\mathrm{pH}$ and plant species richness, with both increasing towards discharge areas (Giesler et al., 1998; Zinko et al., 2005).

Güntner et al. (2004) found that a cta of 6-10 ha worked best for the TWI used to predict water-saturated areas. In our study cta values of 10 to 20 ha generally gave the best correlations for the measured hydrological variables. However, the cta did not have much influence on the strength of the correlations, which may be because most plots were located in non-creek cells regardless of the value of cta. Although Güntner et al. (2004) found a smaller value of cta, indicating that creeks start with less accumulated area, precipitation in their study catchment was roughly twice that in our sites. Kim and Lee (2004) found an optimal cta value of 20 ha for estimation of the creek network in their catchment in South Korea.

Correlation coefficients were in general higher at the HP site than at the LP site. This difference might be explained by the fact that the $\mathrm{pH}$ range in the HP area is greater than that of the LP area, meaning that there is more variation in $\mathrm{pH}$ to be explained by the TWI.

Grouping the variables helped to identify some guiding principles and allow speculating about physical explanations. For instance, higher values for $d$ in the downslope index (i.e., an integration of the slope over a larger scale) gave better results for the correlation with soil $\mathrm{pH}$ and species richness, whereas the local slope worked better for soil moisture. One might argue that this could be because soil $\mathrm{pH}$ and species richness depend more on long-term lateral flow processes that redistribute weathering products within the catchment. In contrast the soil moisture at the surface reflects current conditions and is more sensitive to local topographical features.

\section{Concluding remarks}

This study was a first attempt to find a general calculation method for the TWI that would be valid for the spatial distribution of plant species richness, soil $\mathrm{pH}$, groundwater level, and soil moisture in Fennoscandian boreal forest. We were not able to identify one single best method since different methods gave best correlations with the different measured variables. Although not as pronounced as for the different variables the best methods were also site specific. However, "compromise" methods that yielded best calculations for the different measured variables were identified. In general, the modified Tarboton's flow distribution performed better than Quinn's method, and a low $h$ value yielded the best results. The local slope $\tan \beta$ was found in most cases to be superior to the use of the $\tan \alpha_{d}$ slope. However, a higher $d$ value and the beeline slope distance were best for estimating soil $\mathrm{pH}$ and species richness, while $\tan \beta$ and flow path slope distance were best for estimating the hydrological variables.

It might be useful to explore, if at least some data are available, the variety of calculation methods for the topographical index prior to performing estimates based on it. Our results also indicate the need to further refine the algorithms. Some calculation parameters could be variable in time or space. The value of $c t a$, for instance, could vary with slope or season and the value of $h$ could vary with soil type or slope. The species richness of vascular plants and the $\mathrm{pH}$, however, are not expected to vary seasonally.

Acknowledgements. We thank K. Holmström, Metria, for the interpretation of aerial photographs, and J. Temnerud, J. Lindeberg, Å. Laurell, T. Göthner, L. Ahnby, M. Juutilainen, G. Nordenmark, G. Nilsson, P.-E. Wikberg, G. Brorsson, J. Englund, M. Larsson, E. Carlborg, M. Svedmark and C. Reidy for fieldwork assistance. We also thank N. Hjerdt and K. Bishop for valuable comments, and K. McGlynn for copy editing. Funding for this project was provided by the Swedish Research Council (R. Sørensen and J. Seibert) as well as by the Lamm Foundation, the Foundation for Strategic Environmental Research (MISTRA), the Swedish Research Council for Environment, Agricultural Sciences and Spatial Planning, the Swedish Research Council, J.C. Kempes Minnes Foundation, and Gunnar and Birgitta Nordin's Foundation (UZ).

Edited by: L. Pfister

\section{References}

Band, L. E., Patterson, P., Nemani, R., and Running, S. W.: Forest ecosystem processes at the watershed scale: incorporating hillslope scale, Agr. Forest Meteorol., 63, 93-126, 1993.

Beven, K. J. and Kirkby, M. J.: A physically based, variable contributing area model of basin hydrology, Hydrolological Sciences Bulletin, 24, 43-69, 1979.

Beven, K. J., Wood, E. F., and Sivapalan, M.: On hydrological heterogeneity - catchment morphology and catchment response, J. Hydrol., 100, 353-375, 1988.

Burt, T. and Butcher, D.: Stimulation from simulation - a teaching model of hillslope hydrology for use on microcomputers, J. Geogr. Higher Educ., 10, 23-39, 1986.

Famiglietti, J. S. and Wood, E. F.: Evapotranspiration and runoff from large land areas - land surface hydrology for atmospheric general-circulation models, Surv. Geophys., 12, 179-204, 1991.

Florinsky, I. V., McMahon, S., and Burton, D. L.: Topographic control of soil microbial activity: a case study of denitrifiers, Geoderma, 119, 33-53, 2004.

Giesler, R., Högberg, M., and Högberg, P.: Soil chemistry and plants in Fennoscandian boreal forest as exemplified by a local gradient, Ecology, 79, 119-137, 1998.

Gough, L., Shaver, G. R., Carroll, J., Royer, D. L., and Laundre, J. A.: Vascular plant species richness in Alaskan arctic tundra: the importance of soil pH, J. Ecol., 88, 54-66, 2000. 
Grayson, R. B., Blöschl, G., Western, A. W., and McMahon, T. A.: Advances in the use of observed spatial patterns of catchment hydrological response, Adv. Water Resour., 25, 1313-1334, 2002.

Grubb, P. J.: Global trends in species-richness in terrestrial vegetation: a view from the northern hemisphere, in: Organization of Communities Past and Present, edited by: Gee, J. H. R. and Giller, P. S., Blackwell, pp. 98-118, 1987.

Güntner, A., Seibert, J., and Uhlenbrook, S.: Modeling spatial patterns of saturated areas: an evaluation of different terrain indices, Water Resour. Res., 40, W05114, doi:10.1029/2003WR002864, 2004.

Hjerdt, K. N., McDonnell, J. J., Seibert, J., and Rodhe, A.: A new topographic index to quantify downslope controls on local drainage, Water Resour. Res., 40, W05602, doi:10.1029/2004WR003130, 2004.

Högberg, P., Johannisson, C., Nicklasson, H., and Högbom, L.: Shoot nitrate reductase activities of field-layer species in different forest types, Scand. J. Forest Res., 5, 449-456, 1990.

Holmgren, P.: Topographic and geochemical influence on the forest site quality, with respect to Pinus sylvestris and Picea abies in Sweden, Scand. J. Forest Res., 9, 75-82, 1994a.

Holmgren, P.: Multiple flow direction algorithms for runoff modelling in grid based elevation models: an empirical evaluation, Hydrol. Process., 8, 327-334, 1994b.

Kim, S. and Lee, H.: A digital elevation analysis: a spatially distributed flow apportioning algorithm, Hydrol. Process., 18, 1777-1794, 2004.

Moore, I. D., Grayson, R. B., and Ladson, A. R.: Digital terrain modeling - a review of hydrological, geomorphological, and biological applications, Hydrol. Process., 5, 3-30, 1991.

Moore, I. D., Norton, T. W., and Williams, J. E.: Modelling environmental heterogeneity in forested landscapes, J. Hydrol., 150, 717-747, 1993.

Pan, F., Peters-Lidard, C. D., Sale, M. J., and King, A. W.: A comparison of geographical information system-based algorithms for computing the TOPMODEL topographic index, Water Resour. Res., 40, 1-11, 2004.

Pärtel, M.: Local plant diversity patterns and evolutionary history at the regional scale, Ecology, 83, 2361-2366, 2002.

Quinn, P., Beven, K., Chevallier, P., and Planchon, O.: The prediction of hillslope flow paths for distributed hydrological modeling using digital terrain models, Hydrol. Process., 5, 59-79, 1991.

Quinn, P. F., Beven, K. J., and Lamb, R.: The $\ln (\mathrm{a} / \mathrm{tan}$ beta) index: how to calculate it and how to use it within the TOPMODEL framework, Hydrol. Process., 9, 161-182, 1995.
Raab, B. and Vedin, H.: The national atlas of Sweden: climate, lakes and rivers, SNA Publisher, Stockholm, 1995.

Robson, A., Beven, K., and Neal, C.: Towards identifying sources of subsurface flow: a comparison of components identified by a physically based runoff model and those determined by chemical mixing techniques, Hydrol. Process., 6, 199-214, 1992.

Rodhe, A. and Seibert, J.: Wetland occurrence in relation to topography: a test of topographic indices as moisture indicators, Agr. Forest Meteorol., 98-99, 325-340, 1999.

Sariyildiz, T., Anderson, J. M., and Kucuk, M.: Effects of tree species and topography on soil chemistry, litter quality, and decomposition in Northeast Turkey, Soil Biol. Biochem., 37, 16951706, 2005.

Seibert, J., Bishop, K. H., and Nyberg, L.: A test of TOPMODEL's ability to predict spatially distributed groundwater levels, Hydrol. Process., 11, 1131-1144, 1997.

Sivapalan, M. and Wood, E. F.: A multidimensional model of nonstationary space-time rainfall at the catchment scale, Water Resour. Res., 23, 1289-1299, 1987.

Sivapalan, M., Wood, E. F., and Beven, K. J.: On hydrologic similarity. 3. A dimensionless flood frequency model using a generalized geomorphologic unit hydrograph and partial area runoff generation, Water Resour. Res., 26, 43-58, 1990.

Tarboton, D. G.: A new method for the determination of flow directions and upslope areas in grid digital elevation models, Water Resour. Res., 33, 309-319, 1997.

Whelan, M. J. and Gandolfi, C.: Modelling of spatial controls on denitrification at the landscape scale, Hydrol. Process., 16, 14371450, 2002.

White, J. D. and Running, S. W.: Testing scale-dependent assumptions in regional ecosystem simulations, J. Veg. Sci., 5, 687-702, 1994.

Wolock, D. M. and McCabe, G. J.: Comparison of single and multiple flow direction algorithms for computing topographic parameters in Topmodel, Water Resour. Res., 31, 1315-1324, 1995.

Zinko, U., Seibert, J., Dynesius, M., and Nilsson, C.: Plant species numbers predicted by a topography based groundwater-flow index, Ecosystems, 8, 430-441, 2005.

Zinko, U.: Plants go with the flow - predicting spatial distribution of plant species in the boreal forest, ISBN 91-7305-705-3, PhD thesis, Umeå University, Department of Ecology and Environmental Science, 2004. 